\title{
A exploração espacial dos cometas *
}

Qual é a natureza dos cometas? Esta interrogação foi durante muito tempo precedida por (ou entendida como) uma outra: terão os cometas uma existência permanente? Serão corpos celestes? Duas razðes impediam uma resposta cabal a estas interrogações. Em primeiro lugar o seu movimento no céu. Os cometas não podiam de forma alguma integrar-se no esquema do mundo de Aristóteles porque a excentricidade das suas órbitas era demasiado elevada e o arco de trajectória observado era sempre demasiado pequeno para que se pudesse suspeitar tratar-se de um astro em órbita em torno do outro (o Sol).

O segundo facto era a estranha rapidez com que mudavam de aspecto: não só os cometas podiam diferir fortemente uns dos outros, como um mesmo astro cabeludo se podia transformar com uma rapidez surpreendente ou até mesmo desaparecer (ou aparecer) sem qualquer aviso. No entanto, muitos filósofos gregos haviam reunido factos de observação que permitiam concluir que uma existência efémera seria pouco provável. E alguns deles haviam mesmo levado muito longe as suas deduções sublinhando as inúmeras relações que existiam entre os cometas e o Sol, aparecimentos e desaparecimentos frequentes aos crepúsculo, brilho máximo a uma pequena distância angular do Sol e caudas apontando na direcção oposta à do astro do dia:

Tiveram de passar alguns séculos para os cometas poderem ser considerados, não apenas corpos celestes de comportamento fascinante, mas também entidades físicas cuja natureza seria interessante revelar. O carácter ténue das atmosferas cometárias foi reconhecido quando se verificou a sua incapacidade em ocultar as estrelas; daí a expressiva imagem: "os cometas são nadas visíveis" ('). A presença de grãos de poeira foi deduzida por Arago em 1828 a partir de medidas de polarização da luz emitida, identificada como resultante da reflexão da radiação solar pela matéria sólida. Pouco depois, em 1835, Laplace mostrou, ao estudar a cauda do cometa de Halley, que os grãos de poeira eram expelidos na direç̧ão anti-solar. Cerca de 30 anos mais tarde eram identificados os primeiros constituintes gasosos da cabeleira: eram semelhantes aos das chamas carbonadas.

Ao longo do século $\mathrm{XX}$ foi possível constituir uma ideia mais completa acerca da natureza destes corpos estranhos sem que, no entanto, possamos ter a pretensão de ter desvendado todos os mistérios. A cometologia, assim como a planetologia, benficiou grandemente da revolução que ocorreu nestes domínos de investigação em resultado dos programas espaciais dos dois

(') Em francês, "Les comètes sont des riens visibles" (N.T.). gigantes da exploração espacial, os Estados Unidos e a URSS. Os planetas são objectos de pequenas dimensões, distantes (sendo pois difícil a observação do pormenor das suas superfícies) e quase sempre cobertos por uma expessa camada de matéria absorvente. A estratégia adoptada por americanos e soviéticos (abordar tão próximo quanto possível o objecto em questão com engenhos automáticos e, se possível, efectuar medidas in situ) é por isso fácil de compreender. O par Plutão-Charon, os planetas Neptuno e Urano ( $\left.{ }^{2}\right)$, os asteróides e os cometas são os astros do sistema solar que ainda não receberam a visita próxima de um engenho automático. Os asteróides e os cometas são vestígios supostos intactos dos períodos primitivos do sistema solar.

Há quem considere que existem relações estreitas entre os cometas e os asteróides pelo facto de terem dimensões idênticas e trajectórias frequentemente semelhantes. No entanto, esta similitude não nos leva longe: nada indica que existam cometas cujo núcleo ultrapasse os $10-20 \mathrm{~km}$, situação esta que ocorre nos asteróides. Se compararmos cometas e asteróides do ponto de vista físico verificamos que os asteróides não têm atmosfera no sentido clássico do termo, ao passo que os cometas têm atmosferas que se estendem por milhões de quilómetros. É manifesto que os asteróides resistem perfeitamente às agressões da radiação solar, ao passo que tal não acontece com os cometas. É aliás isto que os distingue de todos os outros objectos do sistema solar e da maior parte dos objectos astrofisicos: são (ou parecem ser) irremediavelmente destruídos pela radiação do astro que os aprisiona gravitacionalmente.

É esta fragilidade térmica que permite o desenvolvimento dos fenómenos cometários. A cabeleira forma-se por evaporação de moléculas ditas "moléculas-mãe", as quais arrastam consigo os grãos que se mantinham cativos na matriz gelada que constitui, no todo ou em parte, o núcleo. A radiação solar actua em quase todos os comprimentos de onda sobre a matéria cometária libertada. Sopra os grãos (primeiros corpos sólidos formados no sistema solar?), o que dá origem à cauda encurvada. Estes grãos atingem rapidamente a nuvem zodiacal. Pode também quebrar as molécula-mãe em átomos e radicais (produtos de degradação) que são detectados porque obsorvem e armazenam essa. mesma radiação, desde o ultravioleta às radiofrequências. A radiação solar pode finalmente ionisar todas estas moléculas e carregar electricamente os grãos. A

\footnotetext{
- Institut d'Astrophysique de Paris.

* Tradução de J.J. Moura Ramos.
}

(2) O planeta Urano acaba de ser visitado pela sonda Voyager 2 que em 24 de Janeiro passou a $81200 \mathrm{~km}$ deste planeta (N.T.). 
interacção entre os iões e o vento solar dá origem à(s) cauda(s) rectilinea(s). Vemos pois que, uma vez aquecidos, os núcleos cometários perdem inevitavelmente parte da sua massa inicial. O fenómeno é tanto mais eficaz quanto a ténue forças gravitacional devida ao núcleo impede a formação de uma atmosfera permanente que poderia retardar esta erosão.

Cometas e asteróides têm pois poucas coisas em comum. Os asteróides não nos deixam ver os constituintes gasosos que eles podem conter oclusos desde a sua formação, ao passo que os cometas persistem em só nos mostrar uma fracção ínfima da sua componente sólida, ainda escondida no seio de um núcleo permanentemente invisível.

A imagem que aqui apresentamos dos cometas (assim como dos asteróides) resulta da análise das propriedades da radiação que estes corpos reflectem. Estes reflectores são na realidade produtos muito degradados das moléculas inicialmente emitidas, e além disso algumas moléculas e radicais são emissores muito fracos, pelo que reconstituir a composição química dos cometas a partir das observações ópticas é um exercício delicado. Nos últimos quinze anos fizeram-se grandes progressos com as observações a partir do espaço $\left(^{3}\right)$. Tornou-se com efeito possivel observar as emissőes de numerosos átomos e radicais que não apresentam assinatura espectral no domínio do visível. Tornou-se então possível uma alternativa elegante à desejada detecção directa das moléculas-mãe (impossível a partir da Terra, mesmo se tentada fora da atmosfera): medindo a abundância de todos os produtos de degradação, é possível deduzir a composição atómica do núcleo. Esta abordagem foi tentada analisando os espectros obtidos com instrumentos colocados em sondas ou satélites em órbita em torno da Terra. E verificou-se que a água era o constituinte dominante na maioria dos objectos estudados. Existem no entanto limitaçð̃es a este método. Alguns radicais e algumas moléculas (como por exemplo $\mathrm{CO}$ e $\mathrm{CO}_{2}$ ) são dificeis de destruir e portanto escapam a esta contabilidade.

Dado o seu elevado nível de actividade, o cometa de Halley vai constituir um alvo de qualidade para os observadores. Se bem que as observações previstas a partir da Terra sejam muito numerosas e diversas, o essencial do esforço a dispender no futuro próximo incidirá sobre a análise in situ da atmosfera do cometa, sobretudo da coma interna que só é possível observar de perto. isto não será inédito, pois em 11 de Setembro de 1985 os Estados Unidos desviavam a sonda ICE (International Cometary Explorer), antiga sonda ISEE-3 que há já vários anos estudava a magnetosfera terrestre, para ir ao encontro do cometa Giacobini-Zinner passando através da sua cauda ionisada. Não se obtiveram imagens do cometa porque a carga útil do ICE era constituída por instrumentos concebidos para estudar plasmas. Por outro lado, a interacção vento solar/plasma cometário foi bem estudada e obtiveram-se informações (impossiveis a partir da Terra) sobre a composição da cauda (ið̃es, electrōes), sobre a velocidade do plasma e sobre a repartição espacial destas partículas.

Uma frota de cinco engenhos espaciais (um europeu, dois soviéticos e dois japoneses) foi lançada ao encontro do cometa de Halley (Tabela 1). Os americanos

( ${ }^{3}$ ) $\mathrm{O}$ autor refere-se à possibilidade de observação dos cometas utilizando instrumentos colocados em satélites, fora da atmosfera terrestre (N.T.). estão ausentes desta grande estreia da exploração espacial apesar de terem sido os primeiros a encarar a realização de uma missão (aliás muito ambiciosa) aos cometas de Halley e Tempel 2. Tiveram que renunciar a ela em consequência dos elevados cortes orçamentais que o programa espacial americano sofreu em 1980.

As cinco sondas são muito diferentes entre si, tanto no seu grau de sofisticação como na perspectiva científica adoptada (Tabela 2). Os instrumentos soviéticos farão uma análise a curta distância, com uma forte capacidade para obter imagens das caudas, da coma e talvez do núcleo, mas as medidas activas (aquelas que implicam uma interacção directa com a matéria cometária) serão bastante limitadas porque a região circum-nuclear não será visitada. Se as informações obtidas no encontro Halley-Vega 1 permitirem prever um risco de destruição reduzido, a sonda Vega 2 passará a 7000 ou mesmo a $5 \mathrm{~km}$ do núcleo. Giotto será o suicida do grupo: será enviada tão perto do núcleo quanto possivel, na esperança não só de que não será destruída antes de ter obtido numerosas informaçōes sobre os ið̃es e espécies neutras da coma interna graças aos seus espectrógrafos de massa, mas sobretudo esperança de que os primeiros impactos com os grãos cometários não a desestabilizarão e de que o seu sinal rádio será sempre recebido na Terra. Dado que é estabilizada por rotação, as imagens serão obtidas ponto por ponto. As sondas japonesas são pelo contrário muito mais simples: MS-T5 estudará a cauda ionizada, longe do núcleo, ao passo que Planet-A registará sobretudo imagens do núcleo atómico de hidrogénio de uma forma quase contínua (a partir de 5 ou 6 de Março encontrará os primeiros átomos de hidrogénio do cometa, os quais terão sido produzidos cerca de dez dias antes). As informações obtidas por todos estes instrumentos serão muito diferentes das obtidas a partir dos nossos observatórios ou de observatórios em órbita terrestre (o satélite IVE será utilizado no domínio do ultravioleta; um foguetão a lançar em meados de Fevereiro obterá um espectro do cometa no seu período de actividade máxima; o vaivém espacial transportaria uma carga útil excepcional durante a grande semana de Março e exploraria da melhor forma possível o dominio ultravioleta). As câmaras fotográficas de Vega e Giotto resolverão a estrutura interna da coma de poeira e dar-nos-ão informaçōes inéditas sobre a actividade do núcleo (zonas emissivas, natureza e estrutura das ejecções, observação da desgaseificação, rotação do núcleo). A câmara infra-vermelho das sondas Vega detectará certamente moléculas-mãe (prevê-se $\mathrm{H}_{2} \mathrm{O}$, $\mathrm{CO}, \mathrm{CO}_{2}, \ldots$ ?) e medirá a emissão térmica dos grãos com grande poder de resolução espacial. O espectrómetro tri-canal (do ultravioleta ao infravermelho próximo) dar-nos-á uma visão completa do espectro da cabeleira e da sua evolução ao longo de alguns dias. A sonda Planet-A completará os objectivos atingidos por Vega obtendo imagens de nuvem de hidrogénio. Os instrumentos da Giotto serão muito mais "activos" no sentido em que quase todos eles implicam um contacto com a matéria cometária. Se a nuvem de poeira que rodeia o núcleo tivesse o bom gosto de não ser opaca, poderíamos mesmo esperar obter imagens do núcleo propriamente dito, com uma resolução espacial da ordem dos 20 metros. Os espectrómetros de massa detectarão certamente iões que não se conseguem detectar a partir da Terra por serem muito pouco numerosos ou fracamente emissivos. Mais de uma dezena de instrumentos vão analisar a interacção vento solar/ionosfera 
Tabela 1

As sondas que explorarão o Cometa de Halley

\begin{tabular}{|c|c|c|c|c|c|}
\hline & Vega-1 (URSS) & Vega-2 (URSS) & Planet-A (Japão) & MS-T5 (Japão) & Giotto (Europa) \\
\hline Data de lançamento.................. & $15 / 12 / 84$ & $21 / 12 / 84$ & Agosto 85 & $8 / 1 / 85$ & $2 / 7 / 85$ \\
\hline Data do encontro ........................ & $6 / 3 / 86$ & $9 / 3 / 86$ & $8 / 3 / 86$ & $11 / 3 / 86$ & $13 / 3 / 86$ \\
\hline Distância mín. encontro $(\mathbf{k m}) . . .$. & $10000\left({ }^{1}\right)$ & $7000(1)$ & $200000(1)$ & $400000\left(^{2}\right)$ & $500\left({ }^{1}\right)$ \\
\hline Velocidade relativa $(\mathrm{km} / \mathrm{s})$.......... & 80 & 77 & 75 & 74 & 69 \\
\hline Peso equip. científico $(\mathbf{k g}) . . . \ldots \ldots$. & 125 & 125 & 12 & 14 & 50 \\
\hline
\end{tabular}

(') Entre o Sol e o núcleo; (²) Na direç̧ão anti-solar.

Tabela 2

Caracteristicas das missões

\begin{tabular}{|c|c|c|c|c|}
\hline & Vega & Giotto & Planet-A & MS-T5 \\
\hline Estabilização ......................................................... & 3 eixos & por rotação & por rotação & por rotação \\
\hline Câmaras fotográficas ................................................. & $\begin{array}{c}3 \\
\text { (visivel e infra- } \\
\text {-vermelho) }\end{array}$ & $\begin{array}{c}1 \\
\text { (Visível) }\end{array}$ & $\begin{array}{c}1 \\
\text { (UV longinquo) }\end{array}$ & - \\
\hline Espectrómetros de massa (espécies neutras e iões)................. & 2 & 2 & - & - \\
\hline espectrómetros de massa (poeira) ..................................... & 1 & 1 & - & - \\
\hline 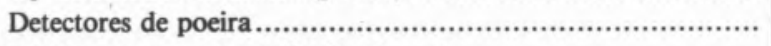 & 1 & 1 & - & - \\
\hline Instrumentos para estudo do plasma................................ & 5 & 4 & 1 & 3 \\
\hline 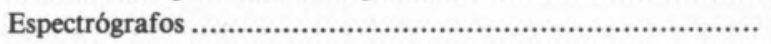 & 1 & - & - & - \\
\hline Outros instrumentos................................................... & - & 1 & - & - \\
\hline
\end{tabular}

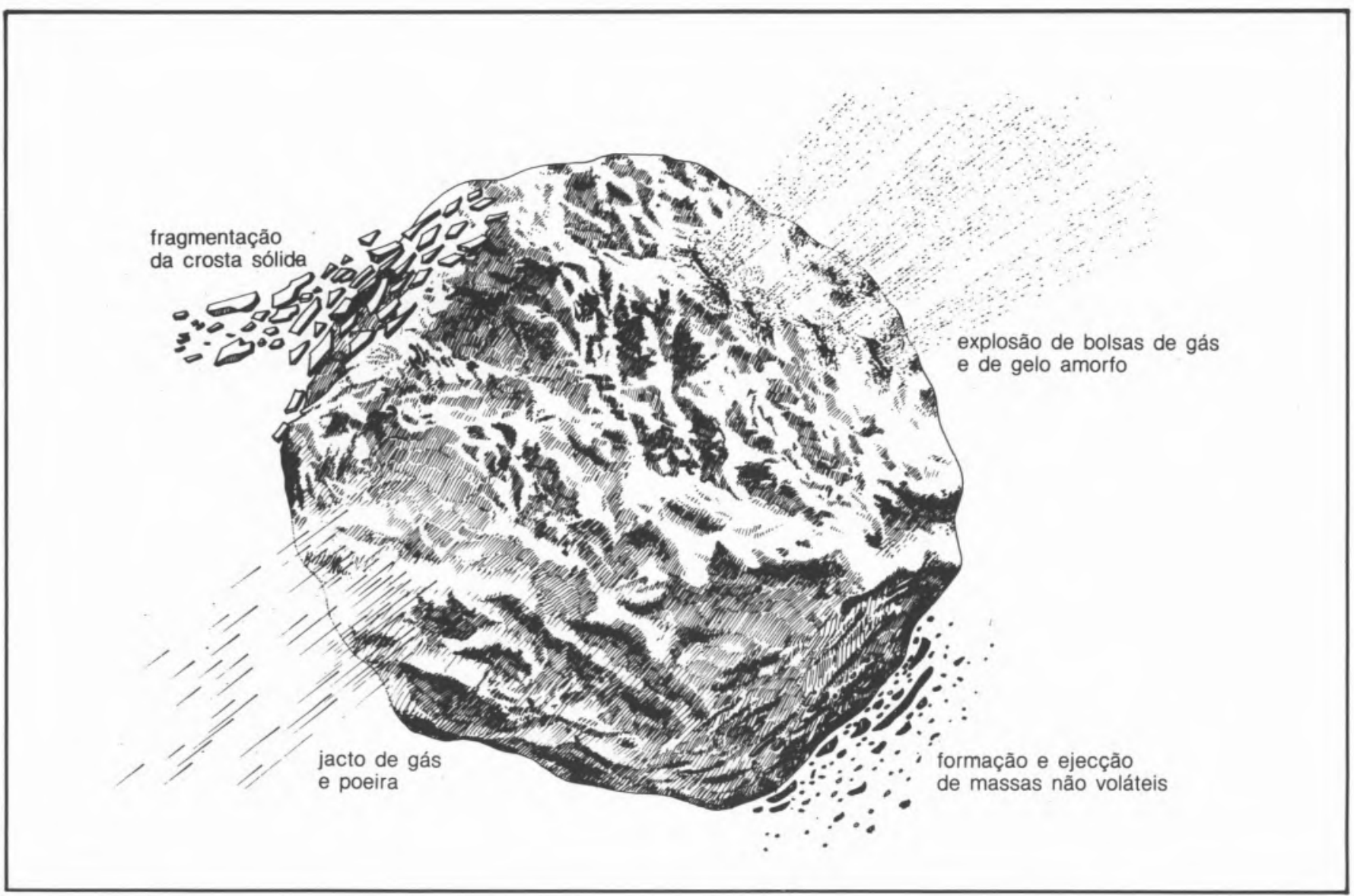

Fig. 1

Os cometas são dos corpos mais antigos do Sistema Solar. A sua parte central (núcleo) encerra dados essenciais sobre as condições reinantes na Nebulosa Solar primitiva, quando da formação dos planetas. Sabe-se ainda muito pouco sobre as constituição e estrutura do núcleo cometário. Segundo o modelo mais aceite, o da "bola de neve suja" ( $F$. Whipple), o núcleo é um aglomerado de rochas e gelo de forma irregular, e com algumas dezenas de quilómetros de extensão. Assim que o cometa se avizinha do Sol, as camadas exteriores deste aglomerado volatilizam-se numa ejecção de gases e poeiras que constitui a parte visível do cometa. Segundo observações recentes esta ejecção não é isotrópica (cf. figura). A sonda Giotto, que se cruzará com o cometa de Halley a 13 de Março, possibilitará a obtenção da primeira imagem de um núcleo cometário. $O$ encontro durará cerca de $4 \mathrm{~h}$, passando a sonda a cerca de $500 \mathrm{~km}$ do núcleo, e a uma velocidade de $250000 \mathrm{~km} / \mathrm{h}$. 